\title{
Effects of a Proactive Interdisciplinary Self-Management Program on Patient Self-Efficacy and Participation During Practice Nurse Consultations: A Randomized Controlled Trial in Type 2 Diabetes
}

\author{
Esther du Pon ${ }^{\mathrm{a}, \mathrm{b}}$, Ad van Dooren ${ }^{\mathrm{a}}$, Nanne Kleefstra ${ }^{\mathrm{c}, \mathrm{d}}$, e, \\ Sandra van Dulmen $\mathrm{f}, \mathrm{g}, \mathrm{h}, \mathrm{i}$
}

\begin{abstract}
Background: Nowadays, patients with chronic conditions such as type 2 diabetes mellitus (T2DM) need and want to be more active participants in their health care. This study aimed to investigate the effects of the Proactive Interdisciplinary Self-Management (PRISMA) training program on participation during consultations with practice nurses and self-efficacy of patients with T2DM in general practice.
\end{abstract}

Methods: Within a randomized controlled trial, patients were followed for 6 months. They received either PRISMA in addition to usual care or usual care only. Self-efficacy was assessed using the 5-item Perceived Efficacy in Patient-Physician Interactions (PEPPI-5) scale. Consultations were video-recorded and analyzed using the Roter interaction analysis system. Multilevel analysis was carried out.

Results: No differences in the PEPPI- 5 were found between the intervention $(n=101)$ and control groups $(n=102)(U=1,737.5, z=-0.2$, $\mathrm{P}=0.8$ ). In addition, the groups did not differ in patient participation. However, patients who attended the PRISMA program expressed more counselling utterances $(B=0.22$; standard error $(S E)=0.09$ ).

Manuscript submitted August 23, 2019, accepted September 12, 2019

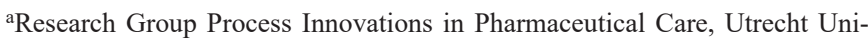
versity of Applied Sciences, Utrecht, the Netherlands

bDiabetes Centre, Isala, Zwolle, the Netherlands

${ }^{c}$ Medical Research Group, Langerhans, Ommen, the Netherlands

${ }^{\mathrm{d}}$ High \& Intensive Care, GGZ Drenthe Mental Health Institute, Assen, the Netherlands

eDepartment of Internal Medicine, University of Groningen and University Medical Center Groningen, Groningen, the Netherlands

${ }_{\mathrm{f}}$ Netherlands institute for health services research (Nivel), Utrecht, the Netherlands

gDepartment of Primary and Community Care, Radboud university medical center, Nijmegen, the Netherlands

hFaculty of Health and Social Sciences, University of South-Eastern Norway, Drammen, Norway

${ }^{\mathrm{i}}$ Corresponding Author: Sandra van Dulmen, Netherlands institute for health services research (Nivel), Otterstraat 118, 3513 CR, Utrecht, the Netherlands. Email: s.vandulmen@nivel.nl

doi: https://doi.org/10.14740/jocmr3965
Conclusions: PRISMA did not result in higher self-efficacy or patient participation during the consultation with practice nurses at 6 months. Possibly, two training sessions are insufficient and a more powerful intervention might be needed. However, the study showed indications that patients counselled themselves more frequently during the consultation. Practice nurses could stimulate patients who are already engaged in self-counselling by further specifying their goals of behavior change.

Keywords: Patient-provider communication; Patient participation; Diabetes type 2; Group education; Self-efficacy; General practice

\section{Introduction}

Today, patients need and want to be more active participants in their health care. This is especially the case for patients with chronic conditions, such as type 2 diabetes mellitus (T2DM).

In the Netherlands, 51 per 1,000 persons are currently affected by T2DM. This rate is expected to increase to 80 per 1,000 inhabitants by 2025 [1]. Patients with T2DM are primarily treated in general practice where they usually see a general practitioner once a year to manage their diabetes and a practice nurse (PN) once to three times a year for routine assessments. In terms of clinical parameters, the quality of the diabetes care provided by a PN is comparable to that provided by a general practitioner [2]. In most patients with T2DM, the cornerstone of the cause and the management of the disease is lifestyle. Treatment success depends on patients' active involvement in self-management behavior and their willingness to adhere to lifestyle advice and medication changes [3]. Therefore, it is important to fully benefit from the consultations with PNs. Due to the absence of perceived disease burden in T2DM, many patients are not encouraged to change their lifestyle and adhere to their medication regimen [4].

Making informed choices about treatment and discussing them with health care providers (HCPs) is one of the core skills in self-management [5]. Active involvement in selfmanagement can be reflected in, among others, a patient's selfefficacy and participation in medical consultations. Because self-efficacy determines the initiation of coping behavior, it is 
a very important precondition for behavioral change [6]. In addition, participation in medical consultations is defined as the extent to which patients contribute to the conversation by, for example, asking questions, expressing concerns, and stating preferences [7]. Many patients with a chronic condition experience at least one barrier to participation, and a considerable portion would like to receive support in communicating with their HCP. Reported barriers to participation include: 1) Not wanting to be bothersome; 2) Perceiving time pressure; and 3) Forgetting discussion topics during the appointment [8]. Skills necessary to overcome these barriers appear to be insufficient in some patients [9]. However, PNs express positive views toward active engagement of their patients [10], which is an important element of shared decision-making [11]. HCPs consider their role to be advisory and aim for patient centeredness.

In the Netherlands, the group-based Proactive Interdisciplinary Self-Management (PRISMA) training program was developed for patients with T2DM in primary care. It was adapted from the Diabetes Education and Self-Management for Ongoing and Newly Diagnosed (DESMOND) program, which was designed in the UK for primary diabetes care [12-14]. One important topic during PRISMA is communication with HCPs; patients are encouraged to prepare for their diabetes consultation and discuss their goals with their HCP. As previous research showed that communication skills training interventions increase patient participation during medical consultations $[15,16]$, this PRISMA topic was expected to improve self-efficacy and participation during PN consultations. This, in turn, is expected to lead to improved health outcomes [17-19]. PRISMA appears to improve self-management behavior in terms of dietary behaviors, foot care, and action planning [20]. In addition, a pilot study showed that the PRISMA program is promising in decreasing dietary intake in newly diagnosed, overweight patients with T2DM in secondary care [14]. However, empirical studies examining the effects of group education on patient self-efficacy and participation during diabetes consultations are lacking.

The present study aimed to investigate the effects of PRISMA on self-efficacy and participation during PN consultations in patients with T2DM treated in general practice. Because communication with HCPs is an important aspect of self-management, a change in participation due to PRISMA can be expected. The primary research question was as follows: what are the effects of PRISMA on patient self-efficacy regarding the communication with their PNs? The secondary research questions were as follows: what are the effects of PRISMA on patient participation during consultations with PNs in terms of asking questions and providing counselling and information on T2DMrelated topics (medical condition, therapeutic regime, lifestyle, and psychosocial issues), and which medical and demographic patient characteristics influence patient participation?

\section{Materials and Methods}

\section{Design}

The current study was part of a larger study, which has been described in detail previously [21]. In short, this study had a randomized controlled trial design in which patients were followed for 6 months. The patients received either PRISMA in addition to usual care or usual care only. A power calculation was carried out on the primary outcome measure (platform use) resulting in 81 participants in both groups [21]. A sample size calculation was not specifically performed for examining effects on self-efficacy and patient participation for the present study. Usual care included a visit to the general practitioner once a year and a visit to their PN one to three times a year to manage their disease. HCPs ask patients about their wellbeing, hypoglycemia or hyperglycemia, diet, physical exercise and medication use. The current study was a video-observation study. After providing PRISMA to the intervention group, the first consultations between the PNs and the patients were recorded by an unmanned camera to analyze their interactions.

This study was reviewed by the Medical Ethics Committee of Isala Hospital (Zwolle, the Netherlands), which decided that, according to Dutch law, formal approval was not necessary (METC no. 14.07104). The study was conducted in accordance with the Declaration of Helsinki and registered at the Dutch Trial Register (no. NTR4693). All participants gave written informed consent. The supporting Consolidated Standards of Reporting Trials (CONSORT) checklist is available as additional information (Supplementary Material 1, www.jocmr.org).

\section{Participants}

Patients aged $\geq 18$ years or older who were diagnosed with T2DM and treated in one of the participating general practices with the general practitioner (GP) defined as their main caregiver were included. Patients with the following conditions that according to the general practitioners may have interfered with trial participation or evaluation of results were excluded [21]: 1) Insufficient knowledge of the Dutch language to understand the requirements of the study and/or the questions posed in the questionnaires; 2) Intellectual disability or psychiatric treatment for schizophrenia; 3) Mental disorder or bipolar disorder; 4) Life expectancy less than 1 year due to malignancies; or 5) Any other serious condition that according to the general practitioners may interfere with trial participation or the evaluation of results.

\section{Recruitment}

Eight general practices in the eastern part of the Netherlands participated in the larger study, of which six also participated in the video-observation portion. Two general practices withdrew due to a heavy workload. The general practitioners selected all eligible patients who were then informed in detail and recruited by the primary investigator (EdP).

\section{Intervention}

The PRISMA program was offered in addition to usual care. PRISMA aims to empower patients by using a nondidactic learning approach. Patients were stimulated to consider their own per- 


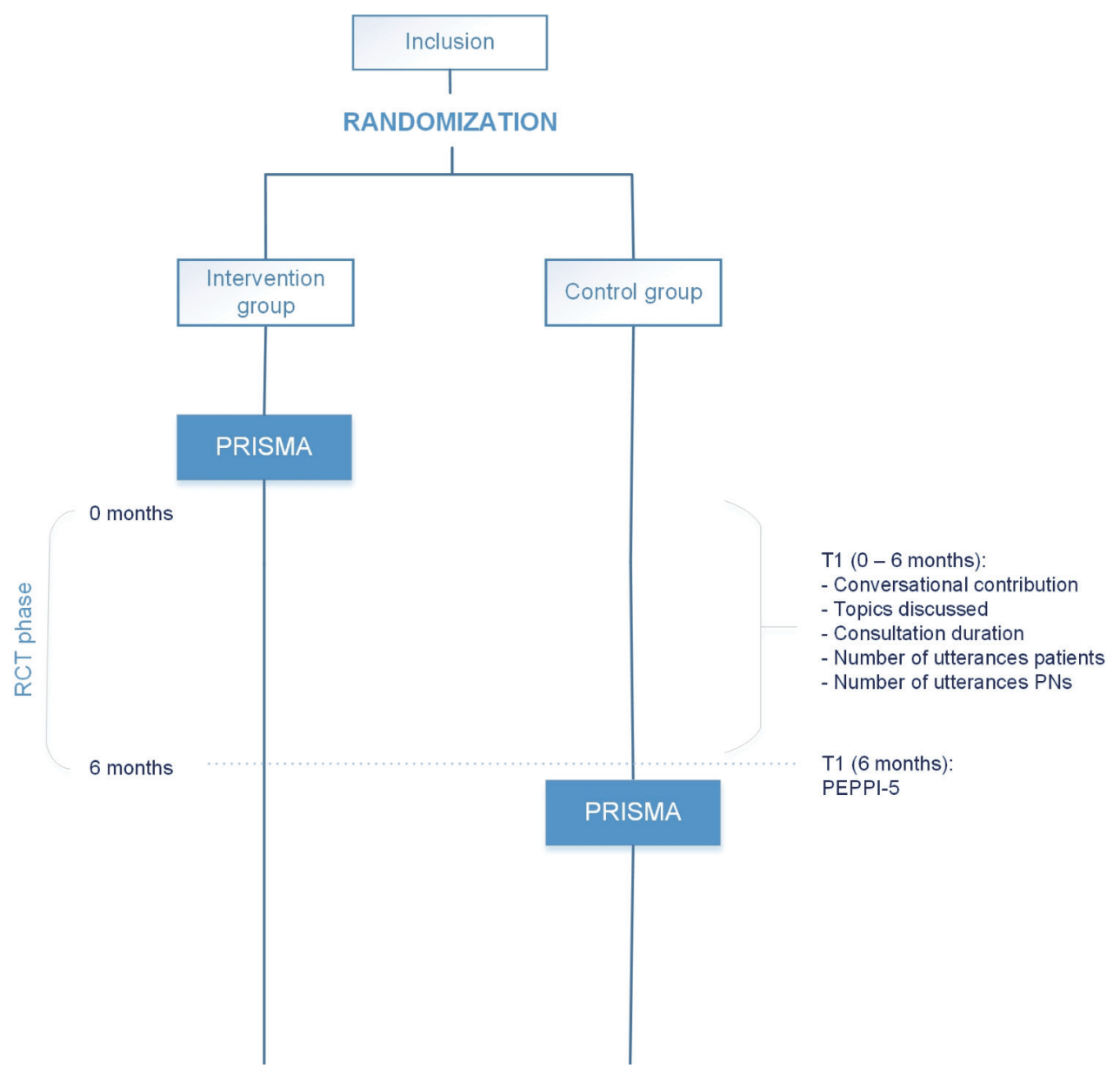

Figure 1. Trial design. RCT: randomized controlled trial; PRISMA: Proactive Interdisciplinary Self-Management; PEPPI: Perceived Efficacy in Patient-Physician Interactions; PN: practice nurse.

sonal risk factors and chose a specific goal of behavior change. The PRISMA program consisted of two sessions of $3.5 \mathrm{~h}$ each. Groups were guided by a dietician and a PN, both experienced in diabetes care. These trainers had followed a standardized training program to ensure the quality of information delivery.

In the first session, the following aspects were covered: individual experiences with T2DM [14], the effect of insulin or oral blood glucose-lowering medication on blood glucose levels, hyperglycemia or hypoglycemia, the monitoring of blood glucose levels, nutrition (carbohydrates), body weight, and stages of behavior change. At the end of the session, patients self-assessed their perceived stage of change given current nutrition and physical activity factors. The second session involved a review of the first session, discussions on complications and personal risk factors, nutrition (fat), physical activity, and the patients' individual diabetes action plans. For the latter, patients chose a specific behavior change goal, such as "I'll take a walk every morning", "I'll quit smoking", or "I will ask two important questions during my next consultation". The last part of the second session specifically focused on communication with the HCPs. The trainers encouraged the patients to consult their HCPs when necessary and stimulated them to think about questions to discuss during future consultations. To help them remember, patients were asked to write down their questions beforehand. The patients were also encouraged to discuss their individual action plans with their HCP during their next consultation and bring up the topics important to them.

In the intervention group, the participants received PRISMA on top of usual care (Fig. 1).

\section{Randomization}

The primary investigator (EdP) performed non-stratified block randomization to assign participants to one of the two groups. The participants were randomized over all general practices in 10 blocks of 20 participants each (10 per group). The blocks were generated by the order of participants' entry (e.g. when 20 participants had applied, they were randomized into two groups). The group assignment was not blinded to participants, the investigator, or the HCP.

\section{Outcomes}

The effects of PRISMA were measured by investigating pa- 
Table 1. The RIAS Codes Applied in the Current Study

\begin{tabular}{|c|c|c|c|}
\hline \multirow{2}{*}{ Task-oriented main topic with sub-categories } & \multicolumn{3}{|c|}{ Communication behavior (examples) } \\
\hline & Asking questions & Informing & Counselling \\
\hline $\begin{array}{l}\text { Medical Information about type } 2 \text { diabetes, tests } \\
\text { to measure blood glucose levels, tests to measure } \\
\text { other health values, other medical information }\end{array}$ & $\begin{array}{l}\text { What is the difference } \\
\text { between type } 1 \text { and } \\
\text { type } 2 \text { diabetes? }\end{array}$ & $\begin{array}{l}\text { I have had diabetes } \\
\text { for } 8 \text { years now. }\end{array}$ & $\begin{array}{l}\text { I am working on decreasing } \\
\text { my blood glucose levels. }\end{array}$ \\
\hline $\begin{array}{l}\text { Therapeutic self-care, the prescription of medicines, } \\
\text { usage of medicines, contact with health care } \\
\text { providers, other therapeutic information }\end{array}$ & $\begin{array}{l}\text { Is there another pill } \\
\text { without side effects } \\
\text { that I could try? }\end{array}$ & $\begin{array}{l}\text { I take these pills } \\
\text { twice a day, and other } \\
\text { pills once a day. }\end{array}$ & $\begin{array}{l}\text { This week I need to make an } \\
\text { appointment for a pedicure. }\end{array}$ \\
\hline $\begin{array}{l}\text { Lifestyle nutrition, physical activity, alcohol use, } \\
\text { smoking, social context, other lifestyle information }\end{array}$ & $\begin{array}{l}\text { How many times a week } \\
\text { do you advise to eat fish? }\end{array}$ & $\begin{array}{l}\text { Sometimes we eat nuts } \\
\text { in between meals. }\end{array}$ & $\begin{array}{l}\text { Now it is time to diminish } \\
\text { our carbohydrate intake. }\end{array}$ \\
\hline $\begin{array}{l}\text { Psychosocial mood, stress, coping with alcohol/ } \\
\text { smoking or diseases, problems with having a } \\
\text { chronic disease, other psychosocial information }\end{array}$ & $\begin{array}{l}\text { Do you think I should } \\
\text { worry about my } \\
\text { forgetfulness? }\end{array}$ & $\begin{array}{l}\text { I feel really desolate } \\
\text { all the time. }\end{array}$ & $\begin{array}{l}\text { I said to myself: the stress } \\
\text { is gone, so I quit smoking. }\end{array}$ \\
\hline
\end{tabular}

RIAS: Roter interaction analysis system.

tient self-efficacy and patient participation during consultations with PNs in terms of asking questions, counselling, providing information on T2DM-related topics, and the extent to which these topics were discussed between patients and PNs. Furthermore, the proportion of utterances made by the patients and PNs was used as a global indicator of conversational contribution. The duration of the consultation was also noted.

\section{Patient self-efficacy}

Patient self-efficacy has been defined as the belief that patients can successfully take appropriate and meaningful action [22]. The self-efficacy of patients when interacting with PNs was assessed using the 5-item Perceived Efficacy in Patient-Physician Interactions (PEPPI-5) survey [23], a validated and reliable measurement of patient self-efficacy for obtaining medical information and physician attention about their medical concerns that is available in Dutch [24]. The PEPPI survey is scored on a scale of 1 (not confident at all) to 5 (completely confident) and contains the items: 1) Get your PN to answer all of your questions?; 2) Make the most of your visit with the PN?; 3) Get your PN to take your chief health concerns seriously?; 4) Know what questions to ask your PN?; and 5) Get your PN to do something about your chief health concern? The developers of the PEPPI have suggested that the instrument could be useful in measuring the impact of empowerment interventions [23].

\section{Patient participation}

Patient participation was subdivided into "conversational contribution" and "topics discussed". To measure conversational contribution, the number of diabetes-specific task-focused verbal utterances made by the patients (questions, counselling, and providing information) was determined. To measure the topics discussed, the extent to which T2DM-related topics (medical, lifestyle, therapeutic, psychosocial) were discussed between patients and PNs was determined by calculating the number of diabetes-specific task-focused verbal utterances per topic. Finally, associations with the following medical and demographical characteristics of patients were investigated: sex, age, diabetes duration, and the presence of a spouse during the consultation.

\section{Video recording}

The PNs were instructed about the use of the camera. The primary investigator (EdP) installed an unmanned video camera, in line with protocol instructions, in the PNs' consulting rooms for the study duration. The recording was started before the patient entered the consulting room and switched off after they left.

\section{Coding procedure}

EdP coded all videos using the Roter interaction analysis system (RIAS), a widely-used international observation system with proven validity and reliability [25-28]. In the RIAS, every HCP and patient utterance is coded in mutually exclusive categories. According to the 2013 RIAS manual [26, 27], "utterances" are defined as the smallest distinguishable speech segment to which a classification may be assigned. The unit may vary in length from a single word to a lengthy sentence. The RIAS distinguishes between affective (socioemotional) and instrumental (task-oriented) behavior. The current study focused exclusively on the latter because we did not expect that PRISMA would influence affective behavior (Table 1). The four primary task-oriented RIAS categories were 1) Medical; 2) Therapeutic; 3) Lifestyle; and 4) Psychosocial. For the purpose of this study, the task-oriented categories were further divided into 20 content categories. According to practice guidelines, these topics were considered relevant for patients with T2DM.

At the start of the coding process, EdP and a second researcher experienced in applying RIAS compared the observations of five video recordings, adjusted unclear items, and made a final coding model. To establish inter-rater reliability, 
$10 \%$ of the same consultations were observed by a third experienced researcher. During the coding process, EdP and the second researcher compared their observations regularly and exchanged coding experiences to check and to reach consensus.

\section{Analysis}

All video recordings were digitalized and analyzed in direct entry software (Observer XT version 7.0-computer system). This computer system is especially designed for coding behavioral interactions from video recordings [29].

\section{Patient self-efficacy}

Patients' self-efficacy in interacting with PNs was assessed at 6 months.

\section{Patient participation}

Video recordings of the first consultation after PRISMA were made. To account for any variation in communication skills between PNs, multilevel models were used which consisted of consultations (level 1) nested within PNs (level 2). Multilevel regression models were used to estimate the frequency of utterances expressed by patients and PNs.

\section{Statistical methods}

Descriptive analyses were used to describe patient and consultation characteristics. Multilevel analysis was carried out to control for the clustering of patients in PNs (with patients (level 1) nested within PNs (level 2)). The first model included patient participation, compared between groups. The second model included whether the patient attended the PRISMA program. To investigate potential associations with patient characteristics, we added sex, age, diabetes duration, and the presence of a spouse during the consultation. Analyses were performed using IBM SPSS Statistics version 22.

\section{Results}

The inclusion period lasted for 9 months (June 2014 to February 2015). Video recordings were made in six of the eight participating general practices. Thirteen PNs recorded their diabetes consultations with participating patients.

The patient flow chart is presented in Figure 2. Of 203 enrolled patients, 101 were randomly assigned to the intervention group while 102 were assigned to the control group. No recordings were available for $24(23.5 \%)$ patients in the intervention group and $29(28.2 \%)$ patients in the control group due to withdrawn consent afterwards or failed or missing recordings. In the intervention group, $71(70.3 \%)$ of 101 patients attended at least one of the two PRISMA sessions. The baseline characteristics did not differ between patients of the participating general practices and those of the non-participating practices. The number of consultations per PN in the sample varied between one and 33 , and $80 \%$ of the PNs had five or less consultations included.

The patient and consultation characteristics are presented in Table 2. In both samples, almost two-thirds of the patients were men aged approximately 70 years. In addition, most patients were moderately educated and visited the $\mathrm{PN}$ alone.

In total, patients expressed 124.0 instrumental utterances (which were observed for this study) per consultation in the intervention group compared to 106.4 in the control group. For both groups, the most common conversational contribution was "providing information" (intervention: 116.7 utterances; control: 100.6 utterances), and the least common was "counselling" (intervention: 0.2 utterances; control: 0.3 utterances). Most utterances were made about the topic "medical" (intervention: 84.5; control: 91.9), and the least utterances were about the topic "psychosocial" (intervention: 10.6; control: 5.6). Consultations in the intervention group took 21.5 (standard deviation (SD), 9.1) min on average compared to 19.6 (SD, 8.3 ) $\mathrm{min}$ in the control group.

\section{Patient self-efficacy}

At 6 months, the median sum score of the PEPPI-5 was 20 (19.0 - 23.0) for the intervention group and 20 (18.0 - 25.0) for the control group. The median score on all five items for both the intervention and control groups was 4.0 (interquartile range, 4.0 - 5.0). No significant differences were found between the groups $(\mathrm{U}=1,737.5 ; \mathrm{z}=-0.2 ; \mathrm{P}=0.8)$.

\section{Patient participation}

Patient participation was subdivided into "patient contribution to the conversation" and "topics discussed". To measure patient contribution to the conversation, the number of diabetesspecific task-focused verbal utterances made by the patients (asking questions, counselling, providing information) was determined. To measure the topics discussed, the extent to which type 2 diabetes related topics (medical, therapeutic, lifestyle, psychosocial) were discussed between patients and practice nurses was determined by calculating the number of diabetesspecific task-focused verbal utterances per topic. Associations with characteristics of patients (sex, age, diabetes duration, and the presence of a spouse during the consultation) were investigated. Table 3 shows the results of the multilevel analysis. The groups did not differ in patient participation in terms of their conversational contribution or the topics discussed. In addition, the consultation duration and number of utterances made by patients and PNs did not differ. However, attending PRISMA showed an effect on the conversational contribution of the patients and the topics discussed. Patients who attended the PRISMA program counselled themselves more often $(\mathrm{B}=$ 0.22 ; standard error $(\mathrm{SE})=0.09)$, discussed their medical con- 


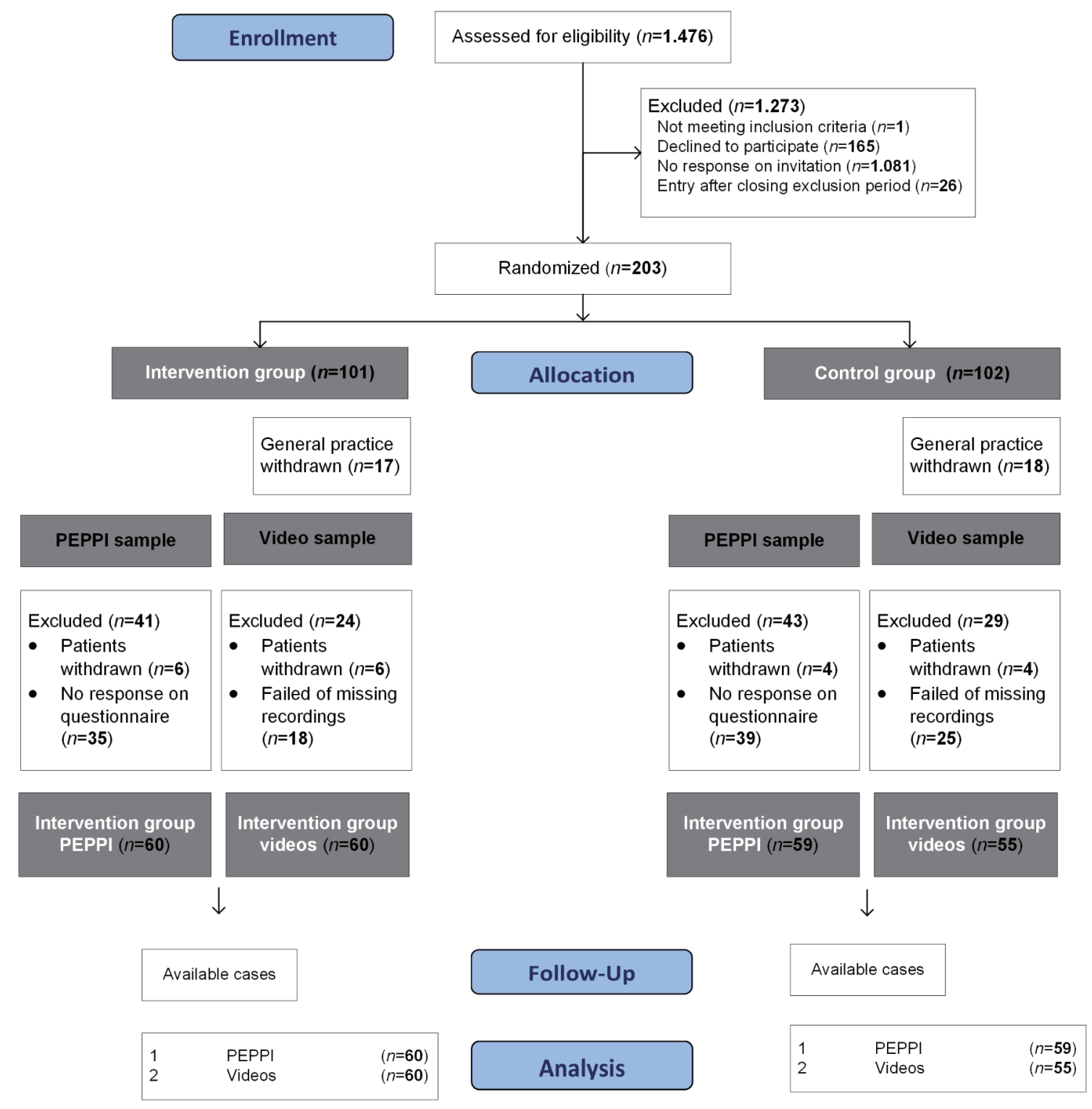

Figure 2. Patient flow chart. PEPPI: Perceived Efficacy in Patient-Physician Interactions.

dition more often $(\mathrm{B}=20.40 ; \mathrm{SE}=9.51)$ and discussed their therapeutic regime less often $(\mathrm{B}=-25.90 ; \mathrm{SE}=9.88)$.

In addition, several associations with medical and demographic characteristics were found. First, diabetes duration and the presence of a spouse showed an effect on the conversational contribution. Patients with a longer diabetes duration provided more information $(\mathrm{B}=3.16 ; \mathrm{SE}=1.17)$, and those who were accompanied by a spouse provided less information $(B=-36.12 ; \mathrm{SE}=13.25)$. Second, the presence of a spouse and longer diabetes duration showed an effect on the topics discussed. Patients who were accompanied by a spouse discussed their medical condition more often $(\mathrm{B}=22.61$; $\mathrm{SE}=11.51)$, and those with a longer diabetes duration discussed their therapeutic regime more often $(\mathrm{B}=2.70 ; \mathrm{SE}=1.02)$. Third, patients accompanied by a spouse had a longer consultation $(\mathrm{B}=4.55 ; \mathrm{SE}=2.11)$. Fourth, duration and the presence of a spouse showed an effect on the number of utterances of patients. Patients with a longer diabetes duration produced more utterances $(\mathrm{B}=3.18 ; \mathrm{SE}=1.26)$, while patients accompanied by a spouse produced less utterances $(B=-42.64 ; \mathrm{SE}=14.53)$.

\section{Discussion}

In general, PRISMA did not change the self-efficacy of patients with T2DM treated in general practice. Moreover, no effects of PRISMA were found on patient participation in terms of their conversational contribution or the topics discussed during the consultation. In addition, the consultation duration and the number of utterances patients and PNs made did not change. However, patients who attended the PRISMA program counselled themselves more frequently during the consultation and 


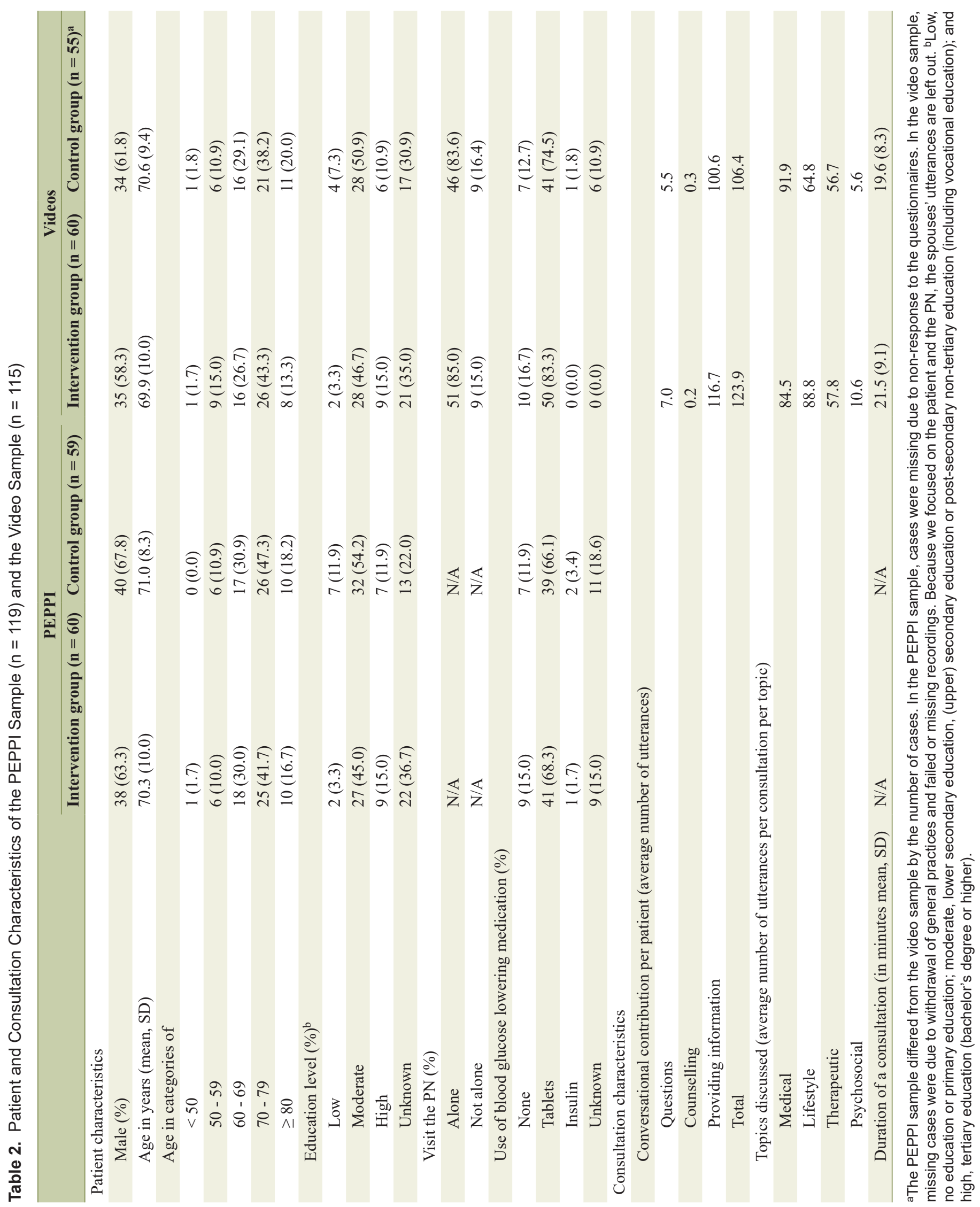




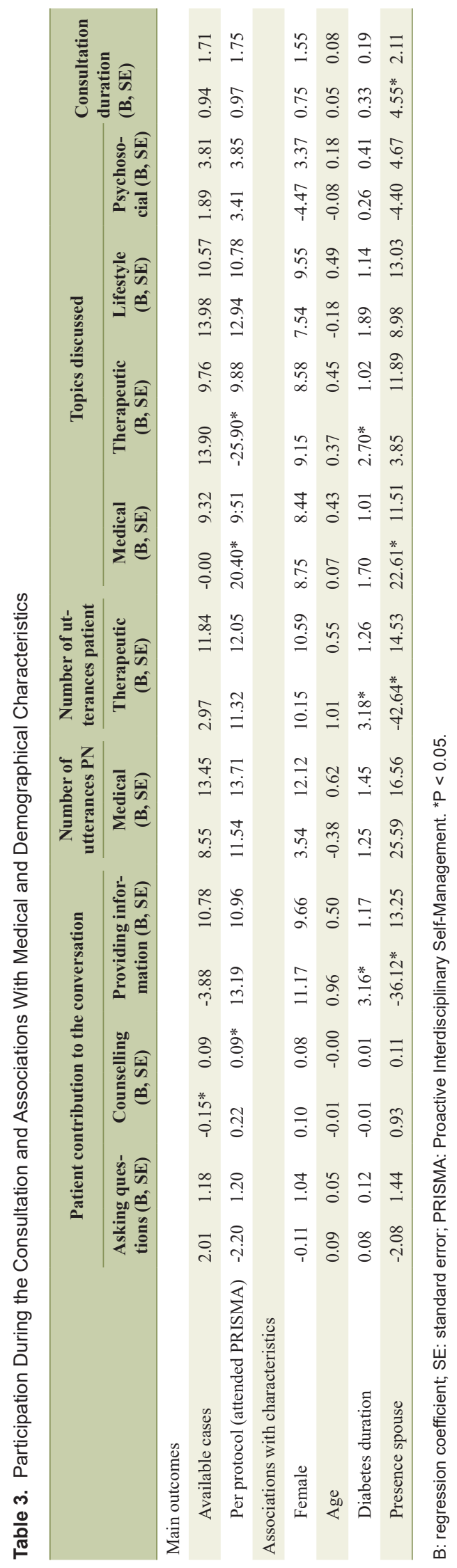

their medical condition was discussed more often while their therapeutic regime was discussed less often. Furthermore, patients with a longer diabetes duration provided more information, and their therapeutic regime was discussed more often. Patients accompanied by a spouse provided less information, and their medical condition was discussed more often.

The patients in our sample did not report better self-efficacy after attending PRISMA. This could be explained by the fact that patients perceived their confidence in medical consultations with their PN as quite high (ceiling effect). In addition, high baseline values are common using the PEPPI-5 [30,31]. According to the literature, improvements on other aspects of self-management behavior (dietary behaviors, foot care and action planning) were found 3 months after PRISMA [20]. Effects in our study may have faded away during the 6-month follow-up period. Health outcomes in diabetes care are usually measured on the longer term. However, the effects of the communication outcomes we were interested in are expected earlier [32]. In addition, effects of diabetes self-management education tend to slowly decline after several months [33]. Therefore, effects on the longer term were not expected.

Our sample consisted primarily of older patients who tend to report greater confidence in interacting with physicians than younger patients [24]. This could be due to their greater experience in communicating with HCPs in general.

In addition, patient participation was not improved by PRISMA. Possibly, two training sessions are insufficient and a more powerful intervention, specifically focused on communication with HCPs, might be needed. An alternative explanation for the lack of effects could be contamination. Generally, PNs in the Netherlands become more and more experienced and follow communication trainings as part of their job. The PNs in our study could also have applied their new mindset to the conversations with the control group. However, there are indications that PRISMA triggered patients to counsel themselves. Examples of self-counselling during the consultation were patient statements such as "I am working on decreasing my blood glucose levels" or "I said to myself: the stress is gone, so I quit smoking". This result is not surprising because during the PRISMA program, patients chose a specific goal of behavior change and were stimulated to discuss their goal(s) with their PN. Patients value the fact that the PNs take them seriously, listen carefully, are open, take sufficient time, and provide adequate advice on how to manage complaints [34, 35]. Therefore, the PNs in our study might have stimulated their already self-counselling patients in further specifying their goals. However, in both groups, counselling did not occur frequently, which could be explained by the fact that patients experience barriers to participation [8].

The knowledge about T2DM gained during the PRISMA program could have triggered patients to talk about (how to improve) their medical condition in general and less about the treatment (medication) because that topic was already wellknown. In addition, possibly, patients' medical condition was discussed more often due to the encouragements of the PRISMA trainers to discuss their specific goal of behavior change with their PNs. The treatment of patients with a longer diabetes duration and thus more experience with the disease might be more complex, supported by results that they provided more 
information and longer discussions about their therapeutic regimen. This suggests that, in time, every patient might evolve from marginally participating patients to active participants. However, a study in cancer care indicated that for some patients such an evolvement is hampered by barriers, such as suboptimal health literacy skills, requiring specific attention by HCPs to engage these patients [36].

Patients accompanied by a spouse provided less information, and their medical condition was discussed more often. Consultations with a spouse meant an extra discussion participant. A logical consequence was that patients gave less information themselves. The finding that the presence of a spouse supports participation is positive because social support is important in diabetes care and a patient never has diabetes alone [37-39]. This result is in agreement with the study by Wolff et al (2015), who investigated whether specific spouse behaviors are helpful in engaging patient participation in medical communication [40]. They found that the presence of a spouse was associated with a more task-focused exchange, particularly by the patient him- or herself.

A strength of this study was the real-life video observation, which is considered optimal for investigating patient participation during consultations [41]. In addition, the influence of the video recorder on the participants' behavior is considered marginal [41]. In six general practices, many video recordings were collected and analyzed which resulted in an extensive data collection. In the current study, 13 PNs recorded their diabetes consultations. Variations in communication skills between PNs, due to characteristics and experience with shared decision-making, were accounted for by using multilevel models.

This study had some limitations. First, although only the first consultations after PRISMA were recorded, it remains unknown what happened during the subsequent consultations after 6 months. Second, in this open-label study, both PNs and patients knew whether a patient followed the PRISMA program. This could have influenced the PNs' communication behavior. Despite detailed instructions given to the PNs, some recording problems did occur, resulting in missing recordings. In these cases, PNs reported that they have forgotten to activate the camera or to replace a full memory card. Third, two general practices withdrew from the study; however, the baseline characteristics did not differ between the patients of the participating and those of the non-participating general practices. Fourth, in the statistical analysis, we did not account for a patient's educational background because the educational levels of many patients were unknown. Fifth, the PEPPI questionnaire was completed by the participants after providing the PRISMA program but not before the training sessions. This could have triggered socially desirable answers on the PEPPI. Sixth, the last part of the second session of PRISMA specifically focused on communication with the HCPs, which was recently added at the start of the study. Therefore, it may not have been internalized sufficiently by the trainers, which could have resulted in less attention to HCP communication than planned.

\section{Conclusions}

The PRISMA program was originally developed to increase self-management behavior in patients with T2DM, of which patient participation during the consultation is an important aspect. PRISMA did not result in higher self-efficacy or patient participation during the consultation with the PN at 6 months, despite the focus on preparing diabetes consultations and discussing goals with PNs. Two training sessions may be insufficient and a more powerful intervention, specifically focused on communication with HCPs, may be needed. However, this study showed indications that PRISMA triggered patients to counsel themselves more frequently during the consultation. In addition, their medical condition appeared to be discussed more often, while their therapeutic regime appeared to be discussed less often.

\section{Practice implications}

HCPs should be prepared for more of a counselling role in consultations of patients with T2DM. In further specifying patient goals of behavior change, they can encourage patients who are already engaged self-counselling to improve their diabetes management. Future research should investigate the effect of PRISMA on consultations with PNs after 6 months. Patients may need more time to manage their health goals and participate more actively.

\section{Supplementary Material}

Suppl 1. CONSORT 2010 Checklist of Information to Include When Reporting a Randomised Trial

\section{Acknowledgments}

We thank the patients for participating and their PNs for recording the consultations with their patients; Janneke Noordman for her training using the RIAS manual and The Observer XT; Richard van Kruysdijk for digitalizing the video recordings; Rodrigo Davids for transporting the coded data to the statistical software package IBM SPSS Statistics; and Daisy Overeem for observing $10 \%$ of the consultations to compute reliability.

\section{Financial Disclosure}

This work was supported by the University of Applied Sciences Utrecht and the Dutch foundation "Care Within Reach" (Stichting Zorg Binnen Bereik). These funding sources had no involvement in the study design, collection, analysis and interpretation of data, writing of this manuscript, or the decision to submit it for publication.

\section{Conflict of Interest}

No potential conflict of interest was reported by the authors. 


\section{Informed Consent}

All participants gave written informed consent. I confirm that all patient/personal identifiers have been removed or disguised so the patient/person(s) described are not identifiable and cannot be identified through the details of the story.

\section{Author Contributions}

EP, AD, NK and SD made substantial contributions to the conception and design, the analysis and interpretation of data, and revising the article critically for important intellectual content. EP was responsible for the acquisition and collection of data and drafting the article. All authors have contributed to and approved the final manuscript. All authors gave final approval of the version to be published and agreed to be accountable for all aspects of the work by ensuring that questions related to the accuracy or integrity of any part of the work are appropriately investigated and resolved.

\section{Data Availability}

The authors declare that data supporting the findings of this study are available within the article (and its supplementary files).

\section{Abbreviations}

T2DM: type 2 diabetes mellitus; PRISMA: Proactive Interdisciplinary Self-Management; DESMOND: Diabetes Education and Self-Management for Ongoing and Newly Diagnosed; RIAS: Roter interaction analysis system; HCP: health care provider; PN: practice nurse; GP: general practitioner; PEPPI-5: 5-item Perceived Efficacy in Patient-Physician Interactions; CONSORT: Consolidated Standards of Reporting Trials

\section{References}

1. Kleefstra N, Landman GW, Van Hateren KJ, Meulepas M, Romeijnders A, Rutten GE, Klomp M, et al. Dutch diabetes prevalence estimates (DUDE-1). J Diabetes. 2016;8(6):863-865.

2. Houweling ST, Kleefstra N, van Hateren KJ, Groenier $\mathrm{KH}$, Meyboom-de Jong B, Bilo HJ. Can diabetes management be safely transferred to practice nurses in a primary care setting? A randomised controlled trial. J Clin Nurs. 2011;20(9-10):1264-1272.

3. van Puffelen AL, Heijmans MJ, Rijken M, Rutten GE, Nijpels G, Schellevis FG, Diacourse study g. Illness perceptions and self-care behaviours in the first years of living with type 2 diabetes; does the presence of complications matter? Psychol Health. 2015;30(11):1274-1287.

4. Hesselink AE, Rutten GE, Slootmaker SM, de Weerdt I, Raaijmakers LG, Jonkers R, Martens MK, et al. Effects of a lifestyle program in subjects with Impaired Fasting Glucose, a pragmatic cluster-randomized controlled trial. BMC Fam Pract. 2015;16:183.

5. Lorig KR, Holman H. Self-management education: history, definition, outcomes, and mechanisms. Ann Behav Med. 2003;26(1):1-7.

6. Bandura A. Self-efficacy. New York: John Wiley \& Sons, Inc. 1994.

7. Street RL, Jr., Millay B. Analyzing patient participation in medical encounters. Health Commun. 2001;13(1):6173.

8. Henselmans I, Heijmans M, Rademakers J, van Dulmen S. Participation of chronic patients in medical consultations: patients' perceived efficacy, barriers and interest in support. Health Expect. 2015;18(6):2375-2388.

9. du Pon E, Wildeboer AT, van Dooren AA, Bilo HJG, Kleefstra N, van Dulmen S. Active participation of patients with type 2 diabetes in consultations with their primary care practice nurses - what helps and what hinders: a qualitative study. BMC Health Serv Res. 2019;19(1):814.

10. Wildeboer A, du Pon E, Schuling J, Haaijer-Ruskamp FM, Denig P. Views of general practice staff about the use of a patient-oriented treatment decision aid in shared decision making for patients with type 2 diabetes: A mixedmethods study. Health Expect. 2018;21(1):64-74.

11. Makoul G, Clayman ML. An integrative model of shared decision making in medical encounters. Patient Educ Couns. 2006;60(3):301-312.

12. Davies MJ, Heller S, Skinner TC, Campbell MJ, Carey ME, Cradock S, Dallosso HM, et al. Effectiveness of the diabetes education and self management for ongoing and newly diagnosed (DESMOND) programme for people with newly diagnosed type 2 diabetes: cluster randomised controlled trial. BMJ. 2008;336(7642):491-495.

13. Gillett M, Dallosso HM, Dixon S, Brennan A, Carey ME, Campbell MJ, Heller S, et al. Delivering the diabetes education and self management for ongoing and newly diagnosed (DESMOND) programme for people with newly diagnosed type 2 diabetes: cost effectiveness analysis. BMJ. 2010;341:c4093.

14. Leibbrandt AJ, Kiefte-de Jong JC, Hogenelst MH, Snoek FJ, Weijs PJ. Effects of the PRo-active Interdisciplinary Self-MAnagement (PRISMA, Dutch DESMOND) program on dietary intake in type 2 diabetes outpatients: a pilot study. Clin Nutr. 2010;29(2):199-205.

15. McGee DS. Patient communication skills training for improved communication competence in the primary care medical consultation. J Appl Comm Res. 1998:26(4):412.

16. Cegala DJ, McClure L, Marinelli TM, Post DM. The effects of communication skills training on patients' participation during medical interviews. Patient Educ Couns. 2000;41(2):209-222.

17. Chen JY, Diamant AL, Thind A, Maly RC. Determinants of breast cancer knowledge among newly diagnosed, low-income, medically underserved women with breast cancer. Cancer. 2008;112(5):1153-1161.

18. Maly RC, Liu Y, Leake B, Thind A, Diamant AL. Treatment-related symptoms among underserved women with breast cancer: the impact of physician-patient communi- 
cation. Breast Cancer Res Treat. 2010;119(3):707-716.

19. Maly RC, Leake B, Mojica CM, Liu Y, Diamant AL, Thind A. What influences diagnostic delay in low-income women with breast cancer? J Womens Health (Larchmt). 2011;20(7):1017-1023.

20. van Vugt M, de Wit M, Bader S, Snoek FJ. Does low well-being modify the effects of PRISMA (Dutch DESMOND), a structured self-management-education program for people with type 2 diabetes? Prim Care Diabetes. 2016;10(2):103-110.

21. Du Pon E, Kleefstra N, van Dooren AA, Bilo HJG, van Dulmen AM. DESTINE: a practice-based intervention to increase empowerment in patients with type 2 diabetes - a study protocol of a randomized controlled trial. Diabetes Manag. 2017;7(4):330-336.

22. Bandura A. The exercise of control. New York: Freeman Company. 1997.

23. Maly RC, Frank JC, Marshall GN, DiMatteo MR, Reuben DB. Perceived efficacy in patient-physician interactions (PEPPI): validation of an instrument in older persons. J Am Geriatr Soc. 1998;46(7):889-894.

24. ten Klooster PM, Oostveen JC, Zandbelt LC, Taal E, Drossaert CH, Harmsen EJ, van de Laar MA. Further validation of the 5-item Perceived Efficacy in PatientPhysician Interactions (PEPPI-5) scale in patients with osteoarthritis. Patient Educ Couns. 2012;87(1):125-130.

25. Ong LM, Visser MR, Kruyver IP, Bensing JM, van den Brink-Muinen A, Stouthard JM, Lammes FB, et al. The Roter Interaction Analysis System (RIAS) in oncological consultations: psychometric properties. Psychooncology. 1998;7(5):387-401.

26. Takekuma Y, Mori A, Kobayashi M, Yamada Y, Sato Y, Narumi K, Furugen A, et al. [Analysis by Using Roter Method of Interaction Process Analysis (RIAS) of the Ability of Pharmacy Students to Communicate after Clinical Training for Pharmacy]. Yakugaku Zasshi. 2018;138(12):1579-1586.

27. Roter D, Larson S. The Roter interaction analysis system (RIAS): utility and flexibility for analysis of medical interactions. Patient Educ Couns. 2002;46(4):243-251.

28. Noordman J, Verhaak P, van Dulmen S. Web-enabled video-feedback: a method to reflect on the communication skills of experienced physicians. Patient Educ Couns. 2011;82(3):335-340.

29. Noldus LP, Trienes RJ, Hendriksen AH, Jansen H, Jansen RG. The Observer Video-Pro: new software for the collection, management, and presentation of time-structured data from videotapes and digital media files. Behav Res
Methods Instrum Comput. 2000;32(1):197-206.

30. Gossec L, Cantagrel A, Soubrier M, Berthelot JM, Joubert JM, Combe B, Czarlewski W, et al. An e-health interactive self-assessment website $(\operatorname{Sanoia}((\mathrm{R})))$ in rheumatoid arthritis. A 12-month randomized controlled trial in 320 patients. Joint Bone Spine. 2018;85(6):709-714.

31. Dy GW, Gore JL, Muncey WW, Ellison JS, Merguerian PA. Comparative effectiveness of a pilot patient-centered ultrasound report in the management of hydronephrosis. J Pediatr Urol. 2018;14(1):57 e51-e57.

32. Henselmans I, de Haes HC, Smets EM. Enhancing patient participation in oncology consultations: a best evidence synthesis of patient-targeted interventions. Psychooncology. 2013;22(5):961-977.

33. Norris SL, Lau J, Smith SJ, Schmid CH, Engelgau MM. Self-management education for adults with type 2 diabetes: a meta-analysis of the effect on glycemic control. Diabetes Care. 2002;25(7):1159-1171.

34. Heiligers PJM, Noordman JC, Korevaar JC, Dorsman S, Hingstman L, van Dulmen AM, de Bakker DH. Praktijkondersteuners in de huisartspraktijk (POH's), klaar voor de toekomst [Practice nurses in general practice, ready for the future?]. Utrecht: NIVEL. 2012.

35. Halcomb EJ, Andrew S. Triangulation as a method for contemporary nursing research. Nurse Res. 2005;13(2):7182.

36. van Bruinessen IR, van Weel-Baumgarten EM, Gouw H, Zijlstra JM, Albada A, van Dulmen S. Barriers and facilitators to effective communication experienced by patients with malignant lymphoma at all stages after diagnosis. Psychooncology. 2013;22(12):2807-2814.

37. Beverly EA, Miller CK, Wray LA. Spousal support and food-related behavior change in middle-aged and older adults living with type 2 diabetes. Health Educ Behav. 2008;35(5):707-720.

38. Glasgow RE, Toobert DJ. Social environment and regimen adherence among type II diabetic patients. Diabetes Care. 1988;11(5):377-386.

39. Rad GS, Bakht LA, Feizi A, Mohebi S. Importance of social support in diabetes care. J Educ Health Promot. 2013;2:62.

40. Wolff JL, Clayman ML, Rabins P, Cook MA, Roter DL. An exploration of patient and family engagement in routine primary care visits. Health Expect. 2015;18(2):188198.

41. Arborelius E, Timpka T. In what way may videotapes be used to get significant information about the patient-physician relationship? Med Teach. 1990;12(2):197-208. 